\title{
Evaluation of chromium bioaccessibility in chromite ore processing residue using in vitro gastrointestinal method
}

\author{
Siwu $\mathrm{Yu}^{\mathrm{a}}$, Jingjing $\mathrm{Du}^{\mathrm{a}}$, Ting Luo ${ }^{\mathrm{a}}$, Yuying Huang ${ }^{\mathrm{b}}$, Chuanyong Jinga,* \\ a State Key Laboratory of Environmental Chemistry and Ecotoxicology, Research Center for Eco-Environmental Sciences, Chinese Academy of Sciences, Beijing 100085, China \\ b Shanghai Synchrotron Radiation Facility, Shanghai Institute of Applied Physics, Chinese Academy of Sciences, Shanghai 201214, China
}

\section{A R T I C L E I N F O}

\section{Article history:}

Received 28 September 2011

Received in revised form

29 December 2011

Accepted 4 January 2012

Available online 11 January 2012

\section{Keywords:}

Chromite ore processing residue

In vitro gastrointestinal method

Bioaccessibility

Cr speciation

Area under the concentration-time curve

\begin{abstract}
A B S T R A C T
Incidental ingestion of Chromite ore processing residue (COPR) particles poses a potential health risk. The purpose of this study was to determine the $\mathrm{Cr}$ bioaccessibility from COPR using the in vitro gastrointestinal (IVG) procedure. The bioaccessible $\mathrm{Cr}(\mathrm{VI})$ was $53.8 \%$ and $42.9 \%$, respectively, in the gastric and intestinal phases from a total of $19490 \mathrm{mg} \mathrm{kg}^{-1} \mathrm{Cr}(\mathrm{VI})$ in COPR. Food intake including milk, dough, and ascorbic acid resulted in a significant decrease in $\mathrm{Cr}(\mathrm{VI})$ bioaccessibility. Some organic acids such as lactic, malic, and citric acid moderately reduced $\mathrm{Cr}(\mathrm{VI})$, while acetic acid exhibited no capacity for $\mathrm{Cr}(\mathrm{VI})$ reduction. The integrated area under the concentration-time curve (AUC) of the IVG extraction was used to calculate bioaccessibility. Compared with the bioaccessibility conventionally estimated using concentrations at the end of the extraction (CEP), the AUC technique should be implemented to confirm the accuracy of the IVG method when reduction of $\mathrm{Cr}(\mathrm{VI})$ occurs during the extraction. The absence of $\mathrm{Cr}(\mathrm{VI})$ phases in extracted residues as evidenced by XANES and XRPD analysis confirmed the $\operatorname{Cr}(\mathrm{VI})$ release and $\mathrm{Cr}(\mathrm{VI})$ reduction by food and ascorbic acid. With readily bioaccessible $\mathrm{Cr}(\mathrm{VI})$ and rapid human uptake, reduction of $\mathrm{Cr}(\mathrm{VI})$ might not be as effective a detoxification pathway as initially thought.
\end{abstract}

(c) 2012 Elsevier B.V. All rights reserved.

\section{Introduction}

Chromite ore processing residue (COPR) is a solid waste generated during the production of hexavalent chromium $(\mathrm{Cr}(\mathrm{VI}))$ by alkaline high-temperature roasting and leaching [1]. Millions of tons of COPR have been deposited in urban areas around the world including UK, USA, India, Pakistan and China [2-4]. $\mathrm{Cr}(\mathrm{VI})$ continues to leach out from sites abandoned over 40 years ago at concentrations of up to $100 \mathrm{mg} \mathrm{L}^{-1}[5,6]$. Various studies have suggested that consumption of $\mathrm{Cr}(\mathrm{VI})$-contaminated drinking water or inhalation of $\mathrm{Cr}(\mathrm{VI})$-contaminated dust could lead to cancer [7]. Based on the urinary $\mathrm{Cr}$ levels following oral administration, the absorption of soluble $\mathrm{Cr}(\mathrm{VI})$ (6.9\%) in humans is 53 times higher than that of soluble $\mathrm{Cr}(\mathrm{III})$ [8]. Besides the lungs and intestinal tract, the liver and kidney are often target organs for $\mathrm{Cr}(\mathrm{VI})$ toxicity [7].

In addition to inhalation and drinking, incidental ingestion of $\mathrm{Cr}$-contaminated soils is a potential important exposure route for nearby residents. For example, over 130 COPR contaminated sites existed in Hudson County, New Jersey, the United States in 1991 [3]. Characterization of house dust in the same county in 1992

\footnotetext{
* Corresponding author. Tel.: +86 106284 9523; fax: +861062849523.

E-mail address: cyjing@rcees.ac.cn (C. Jing).
}

confirmed that household exposure to $\mathrm{Cr}$ occurs near $\mathrm{Cr}$ waste sites [9]. Therefore, accurate evaluation of health risks associated with COPR ingestion presents an urgent need [10]. Thus far there have been few studies of $\mathrm{Cr}$ speciation and dissolution from COPR in the human gastrointestinal tract.

Recently, chemical in vitro extraction methods have been developed as alternatives to the much more expensive in vivo approach to determine bioaccessibility [11-13]. Among various in vitro techniques, the in vitro gastrointestinal (IVG) method proposed by Rodriguez and Basta [14] has been well established to have a close correlation with in vivo results $[13,15]$. Therefore, the in vitro gastrointestinal method was expected to be applicable to potentially harmful elements in general. Most IVG studies calculate bioaccessibility using the concentrations at the end of the gastric or intestinal extraction phases $[12,15,16]$. However, this single time-point IVG method does not explore temporal changes of concentration during the extraction process, suggested as being essential to the accurate determination of bioaccessibility [17].

Chromium speciation presents a unique challenge in precisely deriving the bioaccessible $\mathrm{Cr}$ from COPR. Anionic $\mathrm{Cr}(\mathrm{VI})$, which readily crosses cellular membranes, could be reduced in the human body to cationic $\operatorname{Cr}(\mathrm{III})$, which is incapable of cellular transport and metabolism [18,19]. Simulated synthetic stomach fluids used in bioaccessibility studies could reduce $\mathrm{Cr}(\mathrm{VI})$ through 
a combination of low $\mathrm{pH}$ and soluble organic matter from ingested $\mathrm{Cr}(\mathrm{VI})$-contaminated soil [20]. However, the impact of food ingestion on the rate and extent of $\mathrm{Cr}(\mathrm{VI})$ reduction from COPR per se is poorly understood.

The objectives of this research were to (1) determine $\mathrm{Cr}$ bioaccessibility and speciation in COPR, and (2) study the impact of food and organic acids on the $\mathrm{Cr}$ bioaccessibility. To investigate the health risks of ingested COPR, we compared the $\mathrm{Cr}(\mathrm{VI})$ bioaccessibility conventionally obtained from the concentration at the end of phase (CEP) and from the integrated area under the concentrations-time curve (AUC). X-ray absorption near edge structure spectroscopy (XANES) and X-ray powder diffraction (XRPD) were used to investigate the impact of different organic acids upon the reduction of $\mathrm{Cr}(\mathrm{VI})$ in the simulated gastrointestinal tract.

\section{Materials and methods}

\subsection{Reagents}

Pepsin (cat. no. P7000), bile salt (cat. no. B8631) and pancreatin (cat. no. P1500) from Sigma, Chemical Co., St. Louis, MO were used to simulate the human gastrointestinal fluids. Two kinds of food, powdered milk (Inner Mongolia Yili Industrial Group Co., Ltd., China) and dough (Beijing Guchuan Food Co., Ltd., China) were purchased from a local supermarket. Five organic acids were used in the study, where ascorbic, lactic and malic acids were purchased from Sinopharm Chemical Reagent Co., Ltd. (China), and glacial acetic and citric acids were from Beijing Chemicals Corporation (China). The chemical formulas of these organic acids are shown in Supplementary Data (SD) Fig. S1. All reagents were of analytical reagent grade and were used without further purification. The standard reference material (SRM) of COPR (GSB07-1019-1999) was obtained from the Institute for Environmental Reference Materials of Ministry of Environmental Protection (Beijing, China). Milli-Q water was used in all experiments.

\subsection{COPR sample}

COPR samples were collected from the upper-most layer at an open-air disposal site in Jinan, China. Before its closure in June 2006, the chromate production company had been in business for about 38 years and produced 40000 metric tons per year of chromate using the high-lime procedure, and 60000 metric tons per year of COPR as waste. The samples were thoroughly mixed on a rotator at $40 \mathrm{rpm}$ for $2 \mathrm{~h}$, and then passed through an 80 mesh sieve to obtain small particles $(<200 \mu \mathrm{m})$ which may adhere to the hands for incidental ingestion [14]. The sieved samples were stored in capped containers before use.

\subsection{Characterization}

Total metal contents in COPR were determined according to USEPA method 3051A [21]. The accuracy and precision of this microwave digestion method were validated with the COPR SRM. The soluble metal concentrations were determined using graphite furnace atomic absorption spectrometry (AAS800, Perkin Elmer Co., USA) and inductively coupled plasma optical emission spectrometry (ICP-OES Optima 2000 DV, Perkin Elmer Co., USA). An alkaline digestion test was conducted to determine $\mathrm{Cr}(\mathrm{VI})$ content in solid samples following USEPA method 3060A [22]. Soluble $\mathrm{Cr}(\mathrm{VI})$ concentrations were determined using a Hach DR 2800 spectrophotometer based on USEPA method 7196A [23]. X-ray absorption near edge structure (XANES) spectroscopy was employed to study the $\mathrm{Cr}$ speciation in COPR and in the post-extraction residues. X-ray powder diffraction (XRPD) was applied to examine the mineralogical compositions in COPR and in the extracted residues. The details of XRPD and XANES are summarized in the SD.

\subsection{In vitro gastrointestinal extraction procedure}

Chromium bioaccessibility was evaluated using the IVG method proposed by Rodriguez and Basta [14]. Briefly, 1.2 g COPR was mixed with $180 \mathrm{~mL}$ synthetic gastric fluids in a $250 \mathrm{~mL}$ flask in a water bath at $37^{\circ} \mathrm{C}$. The synthetic gastric juice was composed of $0.15 \mathrm{M} \mathrm{NaCl}$ and $1 \%(\mathrm{w} / \mathrm{v})$ pepsin. Then, the gastric solution $\mathrm{pH}$ was adjusted to and controlled at 1.8 with concentrated $\mathrm{HCl}$ during the entire gastric extraction $(1 \mathrm{~h})$. The solution was purged with nitrogen gas and $1 \mathrm{~mL}$ of antifoam A (Sigma, US) was added to remove the excessive foam. Samples ( $1-\mathrm{mL}$ for each time) were collected at $0,3,5,7,10,15,20,30,45$, and $60 \mathrm{~min}$ in the gastric phase. The samples were centrifuged at $10000 \mathrm{rpm}$ for $5 \mathrm{~min}$, and the supernatant was used to determine soluble $\mathrm{Cr}, \mathrm{Cr}(\mathrm{VI})$, and Fe concentrations. After a 1-h gastric extraction, the solution was adjusted to simulate intestinal fluid by increasing the $\mathrm{pH}$ to 5.5 with saturated $\mathrm{NaHCO}_{3}$ solution and adding $0.35 \%$ porcine bile extract and $0.035 \%$ porcine pancreatin. This intestinal extraction was sustained for another hour. Samples (1-mL for each time) were collected at $3,5,7,10$, $15,20,30,45$, and $60 \mathrm{~min}$ in the intestinal phase, and processed as described above.

Triplicate COPR samples were extracted in parallel experimental settings for quality control purposes. The relative standard deviation (RSD) was calculated as an indication of method precision; generally RSDs of less than $15 \%$ are deemed acceptable. The $\mathrm{Cr}$ bioaccessibility was calculated using the following Eq. (1) [14]:

In vitro bioaccessible $\mathrm{Cr}(\%)=\left[\frac{\text { in vitro extracted } \mathrm{Cr}}{\text { total } \mathrm{Cr}}\right] \times 100$

where in vitro extracted $\mathrm{Cr}$ is the $\mathrm{Cr}$ concentration at the end of the gastric or intestinal phase.

\section{5. $\mathrm{Cr}(\mathrm{VI})$ reduction in IVG solution}

To investigate the possible reduction of $\mathrm{Cr}(\mathrm{VI})$ by the IVG fluid itself, 1 and $30 \mathrm{mg} \mathrm{L}^{-1} \mathrm{Cr}(\mathrm{VI})$ as $\mathrm{K}_{2} \mathrm{CrO}_{4}$ was added into the IVG fluid. Samples were collected at the designated intervals as described above. The samples were centrifuged and the supernatant was used for $\mathrm{Cr}(\mathrm{VI})$ measurements.

\subsection{Impact of food and organic acids}

The effects of dough, milk, and various organic acids on the $\mathrm{Cr}(\mathrm{VI})$ bioaccessibility were examined by adding $60 \mathrm{~g}$ dough [12], $9 \mathrm{~g}$ powdered milk [13], $0.5 \mathrm{~g}$ ascorbic acid, $0.5 \mathrm{~g}$ citric acid, $0.42 \mathrm{~mL}$ lactic acid, $0.5 \mathrm{~g}$ malic acid, and $0.5 \mathrm{~mL}$ acetic acid [24,25], respectively, to separate samples at the beginning of the IVG process.

\section{Results and discussion}

\subsection{COPR characterization}

The metal contents in COPR are shown in Table 1 with the mean value and the standard deviation of triplicate samples. Total $\mathrm{Cr}$ concentrations were $57570 \pm 660 \mathrm{mg} \mathrm{kg}^{-1}$ determined using microwave-assisted acid digestion. The acid digestion method was validated as evidenced by the good agreement between detected and certified values for SRM (Table 1 ). The $\mathrm{Cr}(\mathrm{VI})$ content of $9400 \pm 200 \mathrm{mg} \mathrm{kg}^{-1}$ was obtained using the alkaline digestion. On the other hand, XANES analysis in Fig. 1 shows that $19490 \mathrm{mg} \mathrm{kg}^{-1}$, i.e. approximately $34 \%$ of total $\mathrm{Cr}$, was present as $\mathrm{Cr}(\mathrm{VI})$ in COPR. Consistent with our results, Geelhoed et al. [1] have reported that approximately $30 \%$ of the $\mathrm{Cr}$ in COPR is 
Table 1

Content of major elements in COPR and SRM ( $\left.\mathrm{mg} \mathrm{kg}^{-1}\right)$.

\begin{tabular}{llll}
\hline Element & COPR & SRM \\
\cline { 3 - 4 } & & Detected & Certified $^{\mathrm{b}}$ \\
\hline Total Cr & $57570 \pm 660$ & $34240 \pm 1220$ & $32100 \pm 1300$ \\
$\mathrm{Fe}$ & $55360 \pm 2500$ & $69920 \pm 980$ & $71600 \pm 2600$ \\
$\mathrm{Ca}$ & $168700 \pm 7400$ & $194500 \pm 1600$ & $197000 \pm 7000$ \\
$\mathrm{Mg}$ & $69210 \pm 2750$ & $141700 \pm 800$ & $145000 \pm 7000$ \\
$\mathrm{Na}$ & $30930 \pm 550$ & $10720 \pm 130$ & $11400 \pm 700$ \\
$\mathrm{Al}$ & $28630 \pm 1450$ & $31490 \pm 530$ & $32400 \pm 1600$ \\
$\mathrm{Si}$ & $29110 \pm 1520$ & $28600 \pm 390$ & $28100 \pm 1700$ \\
$\mathrm{Mn}$ & $550 \pm 40$ & $1070 \pm 10$ & $1500 \pm 130$ \\
$\mathrm{Cr}(\mathrm{VI})^{\mathrm{a}}$ & $19490^{\mathrm{a}}$ & & $\mathrm{n} / \mathrm{a}^{\mathrm{c}}$ \\
\hline
\end{tabular}

a Determined with XANES analysis.

b Obtained from SRM.

c Non-available.

in the $\mathrm{Cr}(\mathrm{VI})$ form. The difference in $\mathrm{Cr}(\mathrm{VI})$ percentage obtained with alkaline digestion (16\%) and XANES (34\%) suggests that the alkaline digestion may underestimate the $\mathrm{Cr}(\mathrm{VI})$ content. The observation was in agreement with recent reports comparing the alkaline digestion and XANES analysis [26,27]. Therefore, the $\mathrm{Cr}(\mathrm{VI})$ content determined with XANES $\left(19490 \mathrm{mg} \mathrm{kg}^{-1}\right.$ ) was used in the following bioaccessibility calculations. The mineral assemblage of COPR in this study (Fig. 2) was consistent with COPR mineralogy reported previously for COPR materials from Glasgow and New Jersey [1,27]. $\mathrm{Cr}(\mathrm{VI})$-bearing minerals identified in COPR include stichtite $\left(\mathrm{Mg}_{6} \mathrm{Cr}_{2} \mathrm{CO}_{3}(\mathrm{OH})_{16} \cdot 4 \mathrm{H}_{2} \mathrm{O}\right)$, hydrotalcite $\left(\mathrm{Mg}_{6} \mathrm{Al}_{2}\left(\mathrm{CO}_{3}\right)(\mathrm{OH})_{16} \cdot 4 \mathrm{H}_{2} \mathrm{O}\right)$, katoite $\left(\mathrm{Ca}_{3} \mathrm{Al}_{2}(\mathrm{OH})_{12}\right)$, and calcium aluminum chromium oxide hydrate (CAC) $\left(3 \mathrm{CaOAl}_{2} \mathrm{O}_{3} \mathrm{CaCrO}_{4} \cdot 14 \mathrm{H}_{2} \mathrm{O}\right)$, which are demonstrated hosts for $\mathrm{Cr}(\mathrm{VI})$ in COPR samples through anionic substitution [28-30].

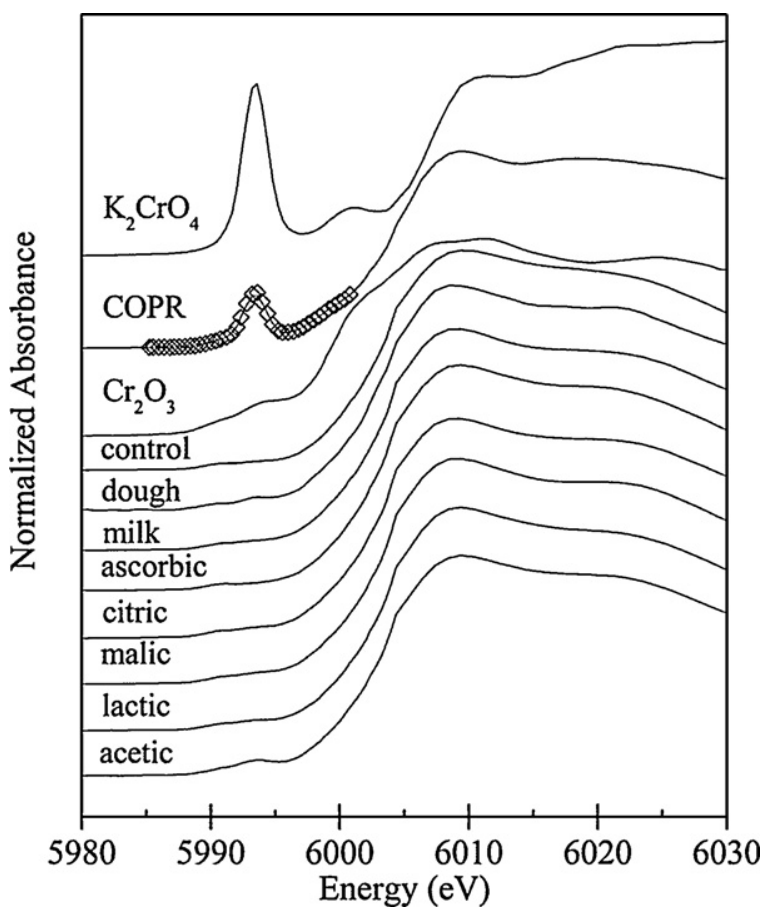

Fig. 1. Chromium K-edge XANES spectra for $\mathrm{K}_{2} \mathrm{CrO}_{4}, \mathrm{COPR}, \mathrm{Cr}_{2} \mathrm{O}_{3}$, IVG extracted residues (control) and various food addition samples including dough, powdered milk, and organic acids such as ascorbic, citric, malic, lactic, and acetic acids. LCF fitting result $(\diamond)$ for COPR: $33 \% \mathrm{Cr}(\mathrm{VI}), 67 \% \mathrm{Cr}(\mathrm{III})$.

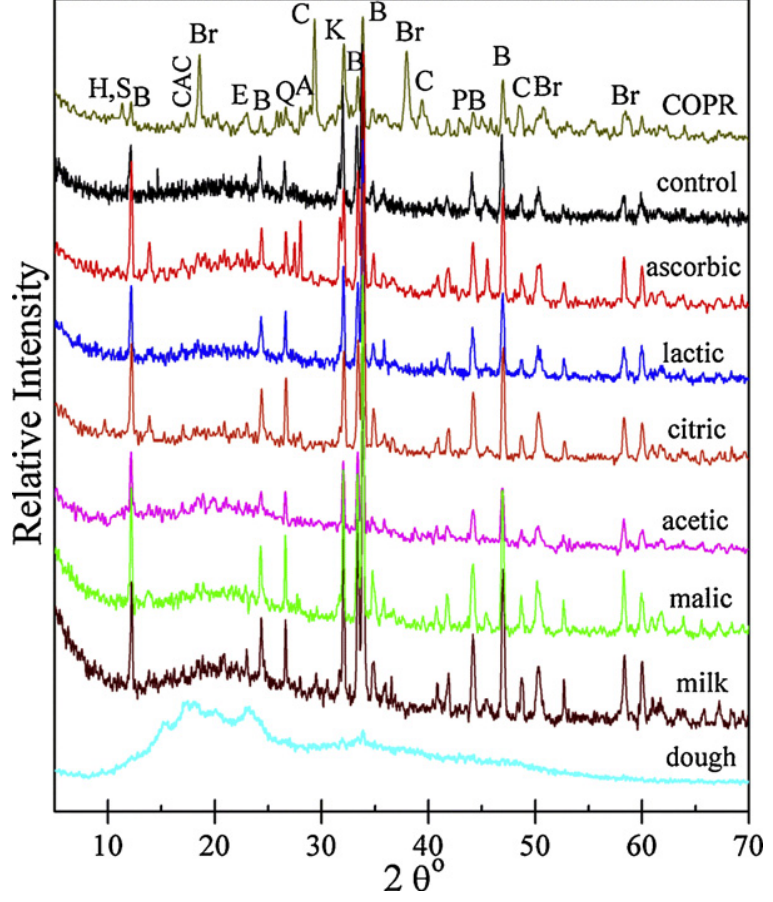

Fig. 2. The XRPD patterns for COPR and IVG-extracted residues with the addition of milk, dough, and ascorbic, citric, malic, lactic, and acetic acids. B: brownmillerite; Br: brucite; Q: quartz; S: stichtite; $\mathrm{H}$ : hydrotalcite; CAC: calcium aluminum oxide chromium hydrate; E: ettringite; K: katoite; C: calcite; A: albite; P: periclase.

\subsection{Reduction of $\operatorname{Cr}(V I)$ in IVG fluids}

No $\mathrm{Cr}(\mathrm{VI})$ reduction occurred when the prepared 1 and $30 \mathrm{mg} \mathrm{L}^{-1} \mathrm{Cr}(\mathrm{VI})$ solutions underwent the IVG extraction (Fig. 3). The observation demonstrates that pepsin, bile, and pancreatin could not reduce $\mathrm{Cr}(\mathrm{VI})$. Our results were also in contrast to a previous hypothesis that ingested $\mathrm{Cr}(\mathrm{VI})$ might be reduced to $\mathrm{Cr}(\mathrm{III})$ because the extreme low $\mathrm{pH}$ condition of the stomach favours the $\mathrm{Cr}(\mathrm{VI})$ reduction $[31,32]$. The Eh-pH diagram (SD Fig. S2) shows that the $\mathrm{Cr}(\mathrm{VI})$ reduction under experimental conditions is thermodynamically feasible. However, the system was not at equilibrium status because of the slow rate of the redox reactions in the absence of foodstuff. Our different findings indicate that any reduction of $\mathrm{Cr}(\mathrm{VI})$ in our bioaccessibility studies on COPR will not have resulted from the IVG fluids themselves. The results highlight the need for further investigation into $\mathrm{Cr}$ speciation and bioaccessibility.

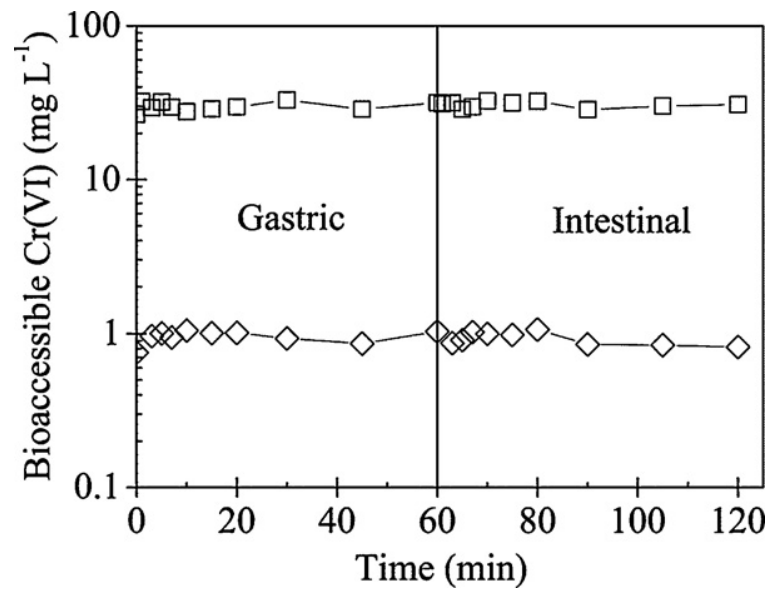

Fig. 3. Change of $\mathrm{Cr}(\mathrm{VI})$ concentrations during the in vitro gastrointestinal extraction with ( $\square) 1$ and $(\diamond) 30 \mathrm{mg} \mathrm{L}^{-1} \mathrm{Cr}(\mathrm{VI})$. 


\subsection{Chromium bioaccessibility}

The bioaccessible $\mathrm{Cr}(\mathrm{VI})$ and $\mathrm{Cr}$ (III) was $53.8 \%$ and $22.6 \%$, respectively, in the gastric phase from the original COPR sample used as a control (Table 2). Nevertheless, the bioaccessibility in the intestinal phase was reduced to $42.9 \%$ for $\mathrm{Cr}(\mathrm{VI})$ and $3.0 \%$ for $\mathrm{Cr}(\mathrm{III})$. The decrease of the $\mathrm{Cr}$ bioaccessibility from the gastric to intestinal phase was coupled with the marked diminution of bioaccessible Fe (Table 2). This observation could be the result of three concurrent reactions as $\mathrm{pH}$ increased from 1.8 in the gastric phase to 5.5 in the intestinal phase: $\mathrm{Cr}$ adsorption on in situ formed iron oxides, $\mathrm{Cr}$ (III) precipitation, and coprecipitation of $\mathrm{Cr}$ and Fe. Meanwhile, our bioaccessibility results were higher than reported values for some $\mathrm{Cr}(\mathrm{VI})$-contaminated soils where reduction by soil organic matter may have played a part [20], suggesting that COPR per se poses a greater health risk.

In the presence of powdered milk and dough, the bioaccessible $\mathrm{Cr}$ (III) was increased in the gastric and intestinal phases (Table 2). On the other hand, the $\mathrm{Cr}(\mathrm{VI})$ bioaccessibility was dramatically reduced by an order of magnitude with the addition of dough and powdered milk. The decrease of bioaccessible $\mathrm{Cr}(\mathrm{VI})$ might be attributed to the reduction of $\mathrm{Cr}(\mathrm{VI})$ by organic components in milk and dough as shown in SD Tables S1 and S2.

The addition of organic acids such as acetic, ascorbic, citric, lactic, and malic acid increased the bioaccessibility of $\mathrm{Cr}$ (III) as compared with the control sample (Table 2). No significant difference was observed for bioaccessible $\mathrm{Cr}(\mathrm{VI})$ between control and acetic acid samples $(n=3, p>0.05)$. With the exception of acetic acid, however, all tested organic acids reduced the $\mathrm{Cr}(\mathrm{VI})$ bioaccessibility. The distinct effects of organic acids could be attributed to their molecular structures (SD Fig. S1). Ascorbic acid resulted in the lowest bioaccessible $\mathrm{Cr}(\mathrm{VI})$ most probably because of its reduction capacity via its hydroxyl groups [33]. $\mathrm{Cr}(\mathrm{VI})$ may be catalytically reduced in the acidic gastric solution by $\alpha-\mathrm{OH}$ carboxylic acids including lactic, citric, and malic acids [34-36]. No $\mathrm{Cr}(\mathrm{VI})$ reduction was observed in the presence of acetic acid because acetic acid contains no $\alpha-\mathrm{OH}$ group [35].

\subsection{Digestion kinetics}

The changes of $\mathrm{Cr}(\mathrm{VI}), \mathrm{Cr}(\mathrm{III})$, and Fe concentrations as a function of digestion time are shown in Fig. 4 for control and food addition samples. A modified calculation method using the integrated area under the concentration-time curve (AUC) was used to determine the bioaccessibility, and the results are listed in Table 2 for comparison with the conventional method using the concentration at the end of phase (CEP). The impact of food ingestion on $\mathrm{Cr}(\mathrm{VI})$ bioaccessibility obtained using AUC was similar to that of CEP (Table 2). Foods could be categorized into three groups based on cluster analysis (SD Fig. S3): foods inert to $\mathrm{Cr}(\mathrm{VI})$ bioaccessibility such as acetic

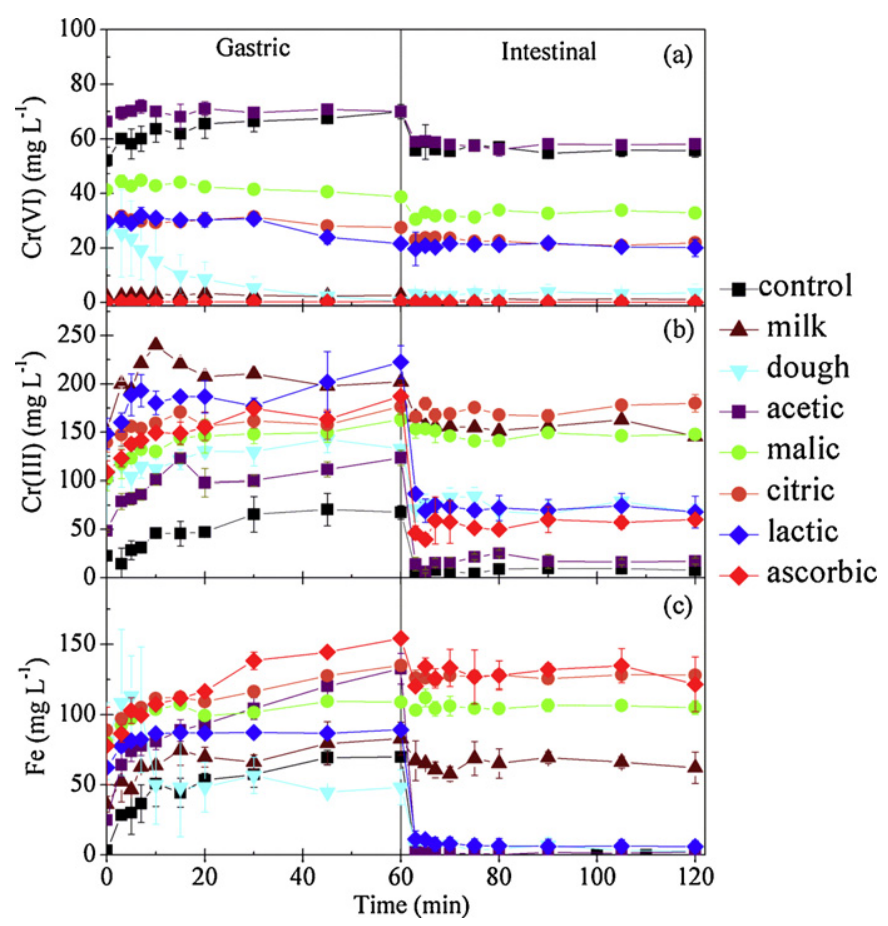

Fig. 4. Kinetics of $\mathrm{Cr}(\mathrm{VI}), \mathrm{Cr}(\mathrm{III})$ and Fe with COPR during the in vitro gastrointestinal extraction. Gastric phase was during 0-60 min; intestinal phase was during 60-120 min. Error bars represent the standard deviation $(n=3)$.

acid; moderate $\mathrm{Cr}(\mathrm{VI})$ reducers such as lactic, citric, and malic acids; and $\mathrm{Cr}(\mathrm{VI})$ scavengers including milk, dough, and ascorbic acid.

A side-by-side comparison between AUC and CEP results demonstrates that the CEP method may inaccurately estimate the Cr bioaccessibility in COPR (Table 2). For example, the CEP method underestimated the bioaccessible $\mathrm{Cr}(\mathrm{VI})$ by an order of magnitude for the dough sample. A close examination of the kinetic data in Fig. 4 suggests that the $\mathrm{Cr}(\mathrm{VI})$ concentration decreased from $27.7 \mathrm{mg} \mathrm{L}^{-1}$ at the beginning of the gastric phase to $0.5 \mathrm{mg} \mathrm{L}^{-1}$ at the end of the intestinal phase. The CEP method assumes that any $\mathrm{Cr}(\mathrm{VI})$ reduction is instantaneous; however, this assumption resulted in an underestimation when redox transformation occurred in $\mathrm{Cr}(\mathrm{VI})$ samples. On the other hand, the CEP method may overestimate the $\mathrm{Cr}$ (III) bioaccessibility when concentrations of $\mathrm{Cr}$ (III) and $\mathrm{Fe}$ increased with time (Fig. 4). In conclusion, the AUC method, which is universally accepted as characteristic of the extent of drug absorption [37,38], should be implemented to confirm the accuracy of the CEP method.

The rate and extent of $\mathrm{Cr}$ release are of equal importance. $\mathrm{Cr}(\mathrm{VI})$ was readily bioaccessible as evidenced by its instantaneous occurrence and unchanged concentrations when COPR was exposed to the simulated gastric juice except for the dough sample (Fig. 4). A

Table 2

Bioaccessibility in gastric and intestinal phases evaluated using CEP and AUC methods.

\begin{tabular}{|c|c|c|c|c|c|c|c|c|c|c|c|c|}
\hline \multirow[t]{3}{*}{ Samples } & \multicolumn{6}{|c|}{ Gastric bioaccessibility (\%) } & \multicolumn{6}{|c|}{ Intestinal bioaccessibility (\%) } \\
\hline & \multicolumn{2}{|l|}{$\mathrm{Cr}(\mathrm{VI})$} & \multicolumn{2}{|l|}{$\mathrm{Cr}(\mathrm{III})$} & \multicolumn{2}{|l|}{$\mathrm{Fe}$} & \multicolumn{2}{|l|}{$\mathrm{Cr}(\mathrm{VI})$} & \multicolumn{2}{|l|}{$\mathrm{Cr}(\mathrm{III})$} & \multicolumn{2}{|l|}{$\mathrm{Fe}$} \\
\hline & CEP & AUC & CEP & AUC & CEP & AUC & CEP & AUC & CEP & AUC & CEP & AUC \\
\hline Control & $53.8 \pm 2.0$ & $50.3 \pm 1.4$ & $22.6 \pm 2.7$ & $22.1 \pm 3.5$ & $18.5 \pm 0.2$ & $17.0 \pm 1.4$ & $42.9 \pm 1.8$ & $46.0 \pm 0.2$ & $3.0 \pm 2.9$ & $13.0 \pm 1.6$ & $0.3 \pm 0.1$ & $0.2 \pm 0.1$ \\
\hline Milk & $2.1 \pm 1.0$ & $2.1 \pm 0.4$ & $79.7 \pm 3.5$ & $81.4 \pm 3.2$ & $22.5 \pm 3.2$ & $56.7 \pm 2.3$ & $1.0 \pm 0.1$ & $1.5 \pm 0.4$ & $57.4 \pm 14.3$ & $71.7 \pm 1.6$ & $16.8 \pm 3.0$ & $49.8 \pm 2.8$ \\
\hline Dough & $0.4 \pm 0.3$ & $6.2 \pm 4.1$ & $52.4 \pm 1.1$ & $50.7 \pm 4.1$ & $13.1 \pm 3.4$ & $35.6 \pm 2.1$ & $2.8 \pm 2.3$ & $4.4 \pm 2.5$ & $26.3 \pm 3.8$ & $40.1 \pm 0.9$ & $0.8 \pm 0.6$ & $28.0 \pm 0.7$ \\
\hline Acetic & $54.0 \pm 1.0$ & $54.0 \pm 0.9$ & $48.7 \pm 3.1$ & $41.1 \pm 1.5$ & $36.0 \pm 3.0$ & $47.2 \pm 1.2$ & $44.8 \pm 1.6$ & $49.4 \pm 0.5$ & $6.8 \pm 1.3$ & $24.6 \pm 1.2$ & $0.6 \pm 0.4$ & $34.2 \pm 1.0$ \\
\hline Malic & $29.8 \pm 1.5$ & $32.1 \pm 0.4$ & $64.3 \pm 2.7$ & $57.0 \pm 2.0$ & $29.5 \pm 0.4$ & $50.5 \pm 1.5$ & $25.3 \pm 0.5$ & $28.7 \pm 0.5$ & $58.2 \pm 0.6$ & $57.5 \pm 1.1$ & $28.4 \pm 1.3$ & $49.6 \pm 0.8$ \\
\hline Citric & $21.2 \pm 0.1$ & $22.8 \pm 0.6$ & $69.5 \pm 3.2$ & $63.3 \pm 1.2$ & $35.6 \pm 1.1$ & $51.6 \pm 1.0$ & $16.9 \pm 1.0$ & $19.9 \pm 0.4$ & $70.9 \pm 3.5$ & $65.7 \pm 06$ & $34.7 \pm 0.9$ & $52.2 \pm 0.6$ \\
\hline Lactic & $16.7 \pm 1.6$ & $20.2 \pm 1.4$ & $87.7 \pm 6.7$ & $75.2 \pm 3.7$ & $24.1 \pm 0.1$ & $59.2 \pm 2.6$ & $15.5 \pm 2.4$ & $18.8 \pm 1.3$ & $26.8 \pm 6.5$ & $52.6 \pm 3.0$ & $1.7 \pm 1.1$ & $42.8 \pm 1.9$ \\
\hline Ascorbic & $0.3 \pm 0.1$ & $0.3 \pm 0.1$ & $73.7 \pm 4.8$ & $63.3 \pm 1.7$ & $41.8 \pm 0.2$ & $43.6 \pm 1.2$ & $0.1 \pm 0.0$ & $0.2 \pm 0.0$ & $23.8 \pm 0.8$ & $43.3 \pm 1.0$ & $32.9 \pm 5.3$ & $29.9 \pm 0.7$ \\
\hline
\end{tabular}


Table 3

Carcinogenic risk (CR) and hazard quotient (HQ) of chromium for children.

\begin{tabular}{|c|c|c|c|c|}
\hline \multirow[t]{2}{*}{ Samples } & \multicolumn{2}{|l|}{ Gastric } & \multicolumn{2}{|l|}{ Intestinal } \\
\hline & $\mathrm{Cr}(\mathrm{VI}) \mathrm{CR}\left(\times 10^{-4}\right)$ & $\mathrm{Cr}(\mathrm{III}) \mathrm{HQ}\left(\times 10^{-3}\right)$ & $\mathrm{Cr}(\mathrm{VI}) \mathrm{CR}\left(\times 10^{-4}\right)$ & $\mathrm{Cr}(\mathrm{III}) \mathrm{HQ}\left(\times 10^{-3}\right)$ \\
\hline Control & $18.6 \pm 0.5$ & $37.3 \pm 5.8$ & $17.3 \pm 0.3$ & $21.9 \pm 2.8$ \\
\hline Milk & $0.8 \pm 0.2$ & $137.4 \pm 5.4$ & $0.6 \pm 0.1$ & $121.0 \pm 7.1$ \\
\hline Dough & $2.3 \pm 1.5$ & $85.6 \pm 6.9$ & $1.6 \pm 0.9$ & $67.7 \pm 1.6$ \\
\hline Acetic & $20.0 \pm 0.5$ & $69.4 \pm 2.6$ & $18.3 \pm 0.2$ & $41.4 \pm 2.0$ \\
\hline Malic & $11.9 \pm 0.2$ & $96.1 \pm 3.4$ & $10.6 \pm 0.2$ & $97.0 \pm 1.8$ \\
\hline Citric & $8.4 \pm 0.3$ & $106.9 \pm 2.0$ & $7.4 \pm 0.1$ & $110.9 \pm 1.1$ \\
\hline Lactic & $7.9 \pm 0.8$ & $126.9 \pm 6.2$ & $7.0 \pm 0.5$ & $88.7 \pm 5.0$ \\
\hline Ascorbic & $0.1 \pm 0.0$ & $106.9 \pm 2.9$ & $0.1 \pm 0.0$ & $73.1 \pm 1.7$ \\
\hline
\end{tabular}

previous study demonstrated a greater absorption of $\mathrm{Cr}(\mathrm{VI})$ than $\mathrm{Cr}$ (III) in the human gastrointestinal tract [8]. With a spontaneous $\mathrm{Cr}(\mathrm{VI})$ release from COPR and the following rapid human uptake, reduction of $\mathrm{Cr}(\mathrm{VI})$ might not be as effective a detoxification pathway as initially thought.

\subsection{Risk assessment}

The chemical daily intake (CDI) was calculated to evaluate the worst case scenario for potential COPR risks to children. The CDI values in the unit of $\mathrm{mg} \mathrm{kg}^{-1} \mathrm{~d}^{-1}$ were determined using the following Eq. (2) [39]:

$\mathrm{CDI}=\mathrm{C} \times \frac{\mathrm{IR} \times \mathrm{EF} \times \mathrm{ED}}{\mathrm{BW} \times \mathrm{AT}}$

where $\mathrm{C}$ is the $\mathrm{Cr}$ concentration in COPR $\left(\mathrm{mg} \mathrm{kg}^{-1}\right)$; IR is the ingestion rate $\left(200 \mathrm{mg} \mathrm{d}^{-1}\right)$ [40]; $\mathrm{EF}$ is the exposure frequency $\left(182 \mathrm{~d} \mathrm{y}^{-1}\right)$ [41]; ED is the exposure duration (4 years for preschool children) [42]; BW is the average body weight (15 kg) [40]; and AT is the averaging time (for non-carcinogens, $\mathrm{AT}=\mathrm{ED} \times 365 \mathrm{~d}$; for carcinogens, $\mathrm{AT}=70 \mathrm{y} \times 365 \mathrm{~d} \mathrm{y}^{-1}=25550 \mathrm{~d}$ ) [39].

The CDI was $7.4 \times 10^{-3} \mathrm{mg} \mathrm{kg}^{-1} \mathrm{~d}^{-1}$ for $\mathrm{Cr}(\mathrm{VI})$, and $0.25 \mathrm{mg} \mathrm{kg}^{-1} \mathrm{~d}^{-1}$ for $\mathrm{Cr}(\mathrm{III})$. The results suggest that the $\mathrm{Cr}(\mathrm{VI})$ intake from COPR was over two times higher than the USEPA oral reference dose $\left(R_{\mathrm{f}} D_{\mathrm{o}}\right)$ of $3 \times 10^{-3} \mathrm{mg} \mathrm{kg}^{-1} \mathrm{~d}^{-1}$ for $\mathrm{Cr}(\mathrm{VI})$ [43] while the $\mathrm{Cr}(\mathrm{III})$ intake was about an order of magnitude lower than the $\operatorname{Cr}$ (III) $R_{\mathrm{f}} D_{\mathrm{o}}$ of $1.5 \mathrm{mg} \mathrm{kg}^{-1} \mathrm{~d}^{-1}$ [43]. However, the above CDI calculation did not consider the impact of food and organic acids on the $\mathrm{Cr}$ bioaccessibility. To include bioaccessibility in the risk assessment, the nondimensional carcinogenic risk (CR) for $\mathrm{Cr}(\mathrm{VI})$ and non-carcinogenic hazard quotient (HQ) for $\mathrm{Cr}(\mathrm{III})$ were calculated using Eqs. (3) and (4), respectively [39,44]:

$\mathrm{CR}=\mathrm{CDI} \times \mathrm{B} \times \mathrm{SF}_{\mathrm{o}}$

$\mathrm{HQ}=\frac{\mathrm{CDI} \times \mathrm{B}}{R_{\mathrm{f}} D_{\mathrm{O}}}$

where $\mathrm{B}$ is the bioaccessibility, and oral cancer slope factor $\left(\mathrm{SF}_{0}\right)$ is $0.5\left(\mathrm{mg} \mathrm{kg}^{-1} \mathrm{~d}^{-1}\right)^{-1}$ [43]. The results listed in Table 3 indicate that the $\mathrm{Cr}(\mathrm{VI}) \mathrm{CR}$ values from COPR were $18.6 \times 10^{-4}$ in the gastric phase and $17.3 \times 10^{-4}$ in the intestinal phase, more than 15 times higher than the safe value $\left(1 \times 10^{-4}\right)$ determined by the USEPA [44]. Among the foodstuffs and organic acids, milk and ascorbic acid could significantly reduce the $\mathrm{CR}$ of $\mathrm{Cr}(\mathrm{VI})$ to a safe value (Table 3 ). Meanwhile, the $\mathrm{Cr}(\mathrm{III}) \mathrm{HQ}$ values from COPR were $37.3 \times 10^{-3}$ in the gastric phase and $21.9 \times 10^{-3}$ in the intestinal phase (Table 3 ). Although food and organic acids increased the HQ for $\mathrm{Cr}$ (III), their values were still much lower than the safe level of 1 established by the USEPA [44].

\subsection{Cr speciation}

The XANES analyses shown in Fig. 1 indicate that no $\mathrm{Cr}(\mathrm{VI})$ was detected in the residues of the IVG extraction. The absence of $\mathrm{Cr}(\mathrm{VI})$ may be due to two reactions. First, $\mathrm{Cr}(\mathrm{VI})$ was released from the solid phase to the artificial gastrointestinal juice. Second, $\mathrm{Cr}(\mathrm{VI})$ was reduced to $\mathrm{Cr}$ (III) with the addition of food and organic acids.

The XRPD patterns for COPR and the IVG-extracted residues are presented in Fig. 2. During extraction, $\mathrm{Cr}(\mathrm{VI})$-bearing minerals, as well as brucite $\left(\mathrm{Mg}(\mathrm{OH})_{2}\right)$, ettringite $\left(\mathrm{Ca}_{6} \mathrm{Al}_{2}\left(\mathrm{SO}_{4}\right)_{3}(\mathrm{OH})_{12} \cdot 26 \mathrm{H}_{2} \mathrm{O}\right)$, periclase $(\mathrm{MgO})$, and calcite $\left(\mathrm{CaCO}_{3}\right)$ were dissolved in the human gastrointestinal tract. Therefore, their characteristic peaks cannot be observed in the XRPD spectra.

Brownmillerite $\left(\mathrm{Ca}_{2}\left(\mathrm{Al}, \mathrm{Fe}^{3+}\right)_{2} \mathrm{O}_{5}\right)$, a $\mathrm{Cr}$ (III)-bearing mineral, was persistently detected in COPR and extraction residue samples (Fig. 4). Furthermore, no new $\mathrm{Cr}$ (III) phases were observed in the residues, which suggests the formation of amorphous rather than crystalline $\mathrm{Cr}(\mathrm{III})$ minerals where $\mathrm{Cr}(\mathrm{VI})$ was reduced.

\section{Conclusions}

Accurate determination of the $\mathrm{Cr}$ bioaccessibility and speciation is of great importance in evaluation of health risks associated with ingested COPR. Our results indicated that $\mathrm{Cr}(\mathrm{VI})$ would not be reduced by the simulated gastrointestinal juice itself. Ingestion of dough, milk, and organic acids including ascorbic, lactic, malic, and citric acid can facilitate the $\mathrm{Cr}(\mathrm{VI})$ reduction in the IVG extraction. Furthermore, XANES and XRPD analysis confirmed the $\mathrm{Cr}(\mathrm{VI})$ reduction with food ingestion. In addition, the conventional method to calculate bioaccessibility using the concentrations at the end of extraction phase could be improved by integrating areas under the concentration-time curve of the IVG extraction.

\section{Acknowledgement}

The research is supported by the National Natural Science Foundation of China (20921063, 20890112, 41023005).

\section{Appendix A. Supplementary data}

Supplementary data associated with this article can be found, in the online version, at doi:10.1016/j.jhazmat.2012.01.009.

\section{References}

[1] J.S. Geelhoed, J.C.L. Meeussen, S. Hillier, D.G. Lumsdon, R.P. Thomas, J.G. Farmer E. Paterson, Identification and geochemical modeling of processes controlling leaching of $\mathrm{Cr}(\mathrm{VI})$ and other major elements from chromite ore processing residue, Geochim. Cosmochim. Acta 66 (2002) 3927-3942.

[2] D. Zhang, S. He, L. Dai, Y. Xie, D. Wu, G. Bu, K. Peng, H. Kong, Impact of pyrolysis process on the chromium behavior of COPR, J. Hazard. Mater. 172 (2009) 1597-1601.

[3] T. Burke, J. Fagliano, M. Goldoft, R.E. Hazen, R. Iglewicz, T. McKee, Chromite ore processing residue in Hudson County, New Jersey, Environ. Health Perspect. 92 (1991) 131-137.

[4] T. Wang, M. He, Q. Pan, A new method for the treatment of chromite ore processing residues, J. Hazard. Mater. 149 (2007) 440-444.

[5] J.G. Farmer, R.P. Thomas, M.C. Graham, J.S. Geelhoed, D.G. Lumsdon, E. Paterson, Chromium speciation and fractionation in ground and surface waters in the 
vicinity of chromite ore processing residue disposal sites, J. Environ. Monit. 4 (2002) 235-243.

[6] J.S. Geelhoed, J.C.L. Meeussen, M.J. Roe, S. Hillier, R.P. Thomas, J.G. Farmer, E. Paterson, Chromium remediation or release? Effect of iron(II) sulfate addition on chromium(VI) leaching from columns of chromite ore processing residue, Environ. Sci. Technol. 37 (2003) 3206-3213.

[7] National Institute of Health, NTP Technical Report on the Toxicology and Carcinogenesis Studies of Sodium Dichromate Dihydrate, Washington, DC, 2007.

[8] B.D. Kerger, D.J. Paustenbach, G.E. Corbett, B.L. Finley, Absorption and elimination of trivalent and hexavalent chromium in humans following ingestion of a bolus dose in drinking water, Toxicol. Appl. Pharmacol. 141 (1996) 145-158.

[9] P.J. Lioy, N.C.G. Freeman, T. Wainman, A.H. Stern, R. Boesch, T. Howell, S.I. Shupack, Microenvironmental analysis of residential exposure to chromium-laden wastes in and around New Jersey homes, Risk Anal. 12 (1992) 287-299.

[10] J.G. Farmer, R. Jarvis, Strategies for improving human health in contaminated situations: a review of past, present and possible future approaches, Environ. Geochem. Health 31 (2009) 227-238.

[11] M.V. Ruby, R. Schoof, W. Brattin, M. Goldade, G. Post, M. Harnois, D.E. Mosby, S.W. Casteel, W. Berti, M. Carpenter, D. Edwards, D. Cragin, W. Chappell, Advances in evaluating the oral bioavailability of inorganics in soil for use in human health risk assessment, Environ. Sci. Technol. 33 (1999) 3697-3705.

[12] J.L. Schroder, N.T. Basta, J.T.Si, S.W. Casteel, T. Evans, M. Payton, In vitro gastrointestinal method to estimate relative bioavailable cadmium in contaminated soil, Environ. Sci. Technol. 37 (2003) 1365-1370.

[13] B. Marschner, P. Welge, A. Hack, J. Wittsiepe, M. Wilhelm, Comparison of soil $\mathrm{Pb}$ in vitro bioaccessibility and in vivo bioavailability with $\mathrm{Pb}$ pools from a sequential soil extraction, Environ. Sci. Technol. 40 (2006) 2812-2818.

[14] R.R. Rodriguez, N.T. Basta, An in vitro gastrointestinal method to estimate bioavailable arsenic in contaminated soils and solid media, Environ. Sci. Technol. 33 (1999) 642-649.

[15] J.L. Schroder, N.T. Basta, S.W. Casteel, T.J. Evans, M.E. Payton, J. Si, Validation of the in vitro gastrointestinal (IVG) method to estimate relative bioavailable lead in contaminated soils, J. Environ. Qual. 33 (2004) 513-521.

[16] P. Pouschat, G.J. Zagury, In vitro gastrointestinal bioavailability of arsenic in soils collected near CCA-treated utility poles, Environ. Sci. Technol. 40 (2006) 4317-4323.

[17] D.G. Beak, N.T. Basta, K.G. Scheckel, S.J. Traina, Bioaccessibility of arsenic(V) bound to ferrihydrite using a simulated gastrointestinal system, Environ. Sci. Technol. 40 (2006) 1364-1370.

[18] S. DeFlora, A. Camoirano, M. Bagnasco, C. Bennicelli, G.E. Corbett, B.D. Kerger Estimates of the chromium(VI) reducing capacity in human body compartments as a mechanism for attenuating its potential toxicity and carcinogenicity, Carcinogenesis 18 (1997) 531-537.

[19] C. Pellerin, S.M. Booker, Reflections on hexavalent chromium - health hazards of an industrial heavyweight, Environ. Health Perspect. 108 (2000) A402-A407.

[20] A. Broadway, M.R. Cave, J. Wragg, F.M. Fordyce, R.J.F. Bewley, M.C. Graham, B.T. Ngwenya, J.G. Farmer, Determination of the bioaccessibility of chromium in Glasgow soil and the implications for human health risk assessment, Sci. Total Environ. 409 (2010) 267-277.

[21] US EPA, Method 3051A, Microwave Assisted Acid Digestion of Sludges, Sediments, Soils, and Oils, Washington, DC, 2007.

[22] US EPA, Method 3060A, Alkaline Digestion for Hexavalent Chromium, Washington, DC, 1996.

[23] US EPA, Method 7196A, Chromium, Hexavalent (Colorimetric), Washington, DC, 1992.

[24] M.V. Ruby, A. Davis, T.E. Link, R. Schoof, R.L. Chaney, G.B. Freeman, P. Bergstrom, Development of an in vitro screening-test to evaluate the in vivo bioaccessibility of ingested mine-waste lead, Environ. Sci. Technol. 27 (1993) 2870-2877.
[25] M.V. Ruby, A. Davis, R. Schoof, S. Eberle, C.M. Sellstone, Estimation of lead and arsenic bioavailability using a physiologically based extraction test, Environ. Sci. Technol. 30 (1996) 422-430.

[26] M. Wazne, A.C. Jappilla, D.H. Moon, S.C. Jagupilla, C. Christodoulatos, M.G. Kim, Assessment of calcium polysulfide for the remediation of hexavalent chromium in chromite ore processing residue (COPR), J. Hazard. Mater. 143 (2007) 620-628.

[27] D. Dermatas, M. Chrysochoou, D.H. Moon, D.G. Grubb, M. Wazne, C. Christodoulatos, Ettringite-induced heave in chromite ore processing residue (COPR) upon ferrous sulfate treatment, Environ. Sci. Technol. 40 (2006) 5786-5792.

[28] S. Hillier, M.J. Roe, J.S. Geelhoed, A.R. Fraser, J.G. Farmer, E. Paterson, Role of quantitative mineralogical analysis in the investigation of sites contaminated by chromite ore processing residue, Sci. Total Environ. 308 (2003) 195-210.

[29] S. Hillier, D.G. Lumsdon, R. Brydson, E. Paterson, Hydrogarnet A host phase for $\mathrm{Cr}(\mathrm{VI})$ in chromite ore processing residue (COPR) and other high $\mathrm{pH}$ wastes, Environ. Sci. Technol. 41 (2007) 1921-1927.

[30] M. Chrysochoou, D. Dermatas, Application of the Rietveld method to assess chromium(VI) speciation in chromite ore processing residue, J. Hazard. Mater. 141 (2007) 370-377.

[31] D.J. Paustenbach, B.L. Finley, F.S. Mowat, B.D. Kerger, Human health risk and exposure assessment of chromium (VI) in tap water, J. Toxicol. Environ. Health - Part A 66 (2003) 1295-1339.

[32] R.E. Wolf, J.M. Morrison, M.B. Goldhaber, Simultaneous determination of $\mathrm{Cr}$ (III) and $\mathrm{Cr}(\mathrm{VI})$ using reversed-phased ion-pairing liquid chromatography with dynamic reaction cell inductively coupled plasma mass spectrometry, J. Anal. Atom. Spectrom. 22 (2007) 1051-1060.

[33] S. Salovaara, A.S. Sandberg, T. Andlid, Organic acids influence iron uptake in the human epithelial cell line Caco-2, J. Agric. Food Chem. 50 (2002) 6233-6238.

[34] B. Deng, A.T. Stone, Surface-catalyzed chromium(VI) reduction: reactivity comparisons of different organic reductants and different oxide surfaces, Environ. Sci. Technol. 30 (1996) 2484-2494.

[35] J. Sun, J.D. Mao, H. Gong, Y. Lan, Fe(III) photocatalytic reduction of $\mathrm{Cr}(\mathrm{VI})$ by low-molecular-weight organic acids with $\alpha-\mathrm{OH}$, J. Hazard. Mater. 168 (2009) 1569-1574.

[36] C. Li, Y.-Q. Lan, B.-L. Deng, Catalysis of manganese(II) on chromium(VI) reduction by citrate, Pedosphere 17 (2007) 318-323.

[37] K. Yamaoka, T. Nakagawa, T. Uno, Statistical moments in pharmacokinetics, J. Pharmacokinet. Pharmacodyn. 6 (1978) 547-558.

[38] J.D. Ma, E.T. Nguyen, S.M. Tsunoda, H.E. Greenberg, J.C. Gorski, S.R. Penzak, L.S. Lee, Assessment of oral midazolam limited sampling strategies to predict area under the concentration time curve (AUC) during cytochrome P450 (CYP) 3A baseline, inhibition and induction or activation, Int. J. Clin. Pharmacol. Ther. 48 (2010) 847-853.

[39] X. Hu, Y. Zhang, J. Luo, T. Wang, H. Lian, Z. Ding, Bioaccessibility and health risk of arsenic, mercury and other metals in urban street dusts from a mega-city, Nanjing, China, Environ. Pollut. 159 (2011) 1215-1221.

[40] US EPA, Supplemental Guidance for Developing Soil Screening Levels for Superfund Sites, OSWER 9355, Washington, DC, 2002, pp. 4-24.

[41] US EPA, Exposure Factors Handbook, Volume I: General Factors, EPA 600-P-95002Fa, Washington, DC, 1997.

[42] US EPA, Cancer Risk Calculations, Handbook for Implementing the Supplemental Cancer Guidance at Waste and Cleanup Sites. Available at: http://www.epa.gov/oswer/riskassessment/sghandbook/riskcalcs.htm.

[43] US EPA, Region 9, Regional Screening Levels 2011 Table (Industrial Soil Supporting), Available at: http://www.epa.gov/region9/superfund/prg/index.html.

[44] US EPA, Guidance for Evaluating the Oral Bioavailability of Metals in Soils for use in Human Health Risk Assessment, OSWER 9285, Washington, DC, 2007, pp. 7-80. 